\title{
SIMULATION TESTS OF PERIPHERAL FRICTION BRAKE USED IN AGRICULTURAL MACHINERY SHAFTS
}

\author{
Andrzej Borawski, Grzegorz Mieczkowski, Dariusz Szpica \\ Bialystok University of Technology, Poland \\ a.borawski@pb.edu.pl,g.mieczkowski@pb.edu.pl,d.szpica@pb.edu.pl
}

\begin{abstract}
Shafts are commonly used parts in agricultural machinery. They are responsible for transmitting the torque from the power source to the receiver, which can be, e.g. a mower blade, hydraulic pump or something completely different. In the agricultural industry, where the operator is very often near a rotating part, it is important to have the ability to quickly stop the rotating shaft. This has a direct impact on work safety. Therefore, the health or even life of both the operator and third parties nearby may depend on the proper functioning of the braking system. A characteristic feature of all friction brakes is their heating up during operation. High rotational speeds of shafts combined with the need to quickly stop the rotational element can lead to the generation of very high temperatures in the friction node. Overheating the brake can lead to the socalled fading phenomenon, which reduces the value of the friction coefficient practically to zero. The purpose of the work was to develop a mathematical model of the agricultural machine shaft breaking process and check how the initial speed affects the heating of friction steam. In this work, a mathematical model of a typical peripheral brake was developed, and simulation tests of the shaft braking process from different initial speeds based on it were performed. The $\mathrm{CAD}$ model of the brake and the finite element method were used to determine temperature profiles. It was also assumed that the inertia resulting from the non-zero mass of the system is constant for all cases. The stopping time was also the same for each case. The obtained results allow to assess the dependence of heating on the initial rotation speed of the shaft, and the developed model can be extremely helpful at the design stage of agricultural machinery.
\end{abstract}

Keywords: mechanical engineering, brakes, friction, agricultural machinery.

\section{Introduction}

Agricultural machinery of various types and sizes are widely used in today's agricultural industry $[1 ; 2]$. This is due to, among others, growing farm acres [3]. They are usually driven through the PTO shaft by the internal combustion engine of the agricultural tractor $[4,5]$. There is a certain rotational speed and a certain torque at the input of the device. In the most cases they are transmitted to the rest of the device by using shafts, which can be connected by various types of gears (traction, gear, friction, etc.) or clutches [6; 7]. Ultimately, the drive goes to the receiver, which can be, e.g. a cutting knife, press or any other device.

Most of moving parts of agricultural machines are made of steel [8]. It is a very good construction material, but it has a high density, which simply makes the components heavy [9-11]. In turn, mass affects inertia [12-14]. The high inertia of the rotating elements means that both their acceleration and stopping require significant amounts of energy [15]. For the drive, as already mentioned, the energy generated by the farm tractor engine is needed. For stopping, the phenomenon of friction is most often used [16-19]. In both cases, energy conversion takes place. During acceleration, the chemical energy of the fuel is converted into the kinetic energy of the rotating element [20-23], while during braking, because of the friction, kinetic energy is converted into thermal energy [24].

For agricultural machinery shafts, the most common brake solution is peripheral friction brakes. They are made of a friction pair, which is a disc as an integral part of the shaft or an element mounted on the shaft, and a belt that clamps on the plug when braking.

As a result of their cooperation, kinetic energy is converted into thermal energy, which is then discharged into the atmosphere and into the immediate surroundings (to nearest elements of the structure). Unfortunately, large amounts of heat can be harmful $[25 ; 26]$. A real threat of the phenomenon of the so-called fading appears, as a result of which the value of the coefficient of friction drops practically to zero [27].

In this work, it was decided to check how the initial rotational speed of the shaft affects the course of the friction pair heating process during emergency stopping of the rotary mower shaft.

\section{Materials and methods}


The research object was the main working shaft of a popular rotary mower in Poland equipped with a peripheral brake. The brake disc is a separate element mounted on the shaft using shape connection. The shaft assembly diagram is shown in Fig. 1.

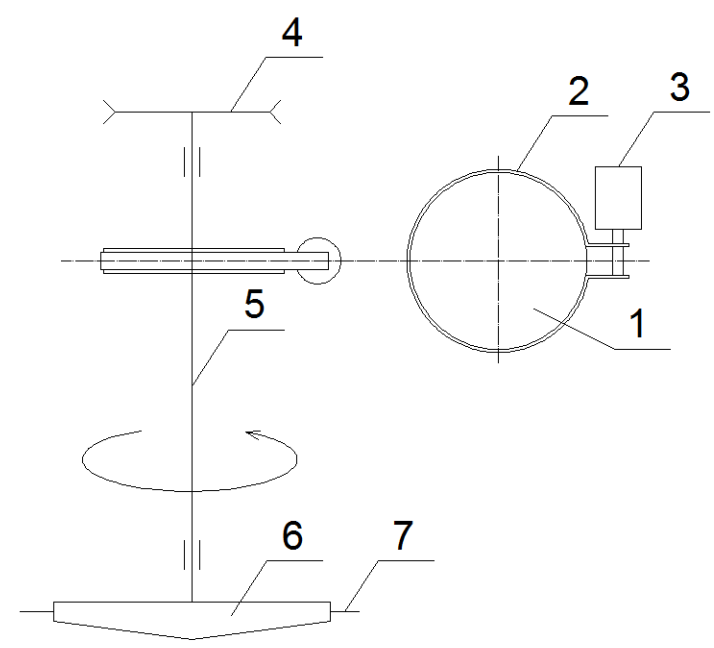

Fig. 1. Scheme of the test object: 1 - disc acting as a flywheel and brake element; 2 - brake band; 3 - brake actuator; 4 - belt drive pulley (shaft source of drive); 5 - mower shaft; 6 - mower disk;

7 - cutting knives

The CAD model (Fig. 2) of the tested element (the shaft brake) was developed (using SolidWorks) and then it was tested by using FEM. Simplification consisted in removing elements that do not have a significant impact on the test results (like shaft inlet connection or bends in the strap for attaching the actuator). Otherwise it could introduce unnecessary high mesh density, and thus - among others, extension of the test time. It was also assumed that the nominal curb weight of the braking element is $46 \mathrm{~kg}$.

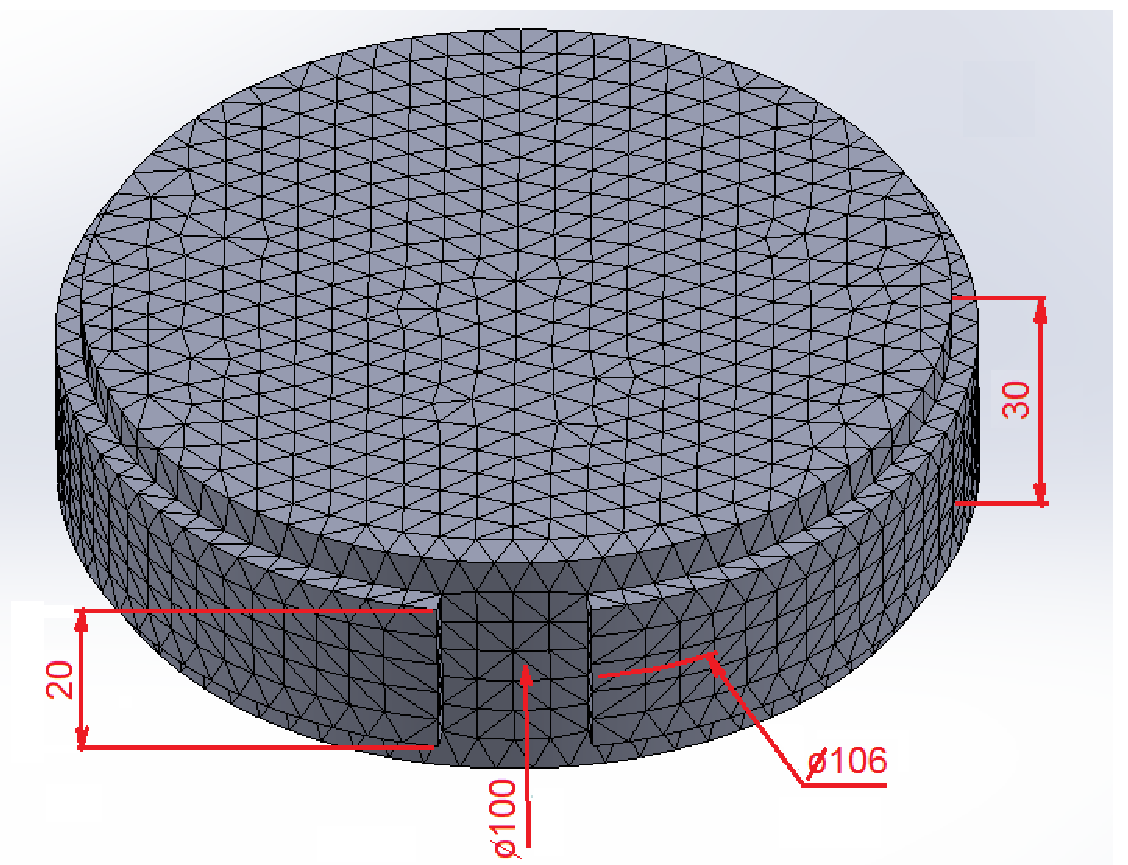

Fig. 2. Simplified CAD model of the shaft brake

The brake disc material is cast iron, and the band material is metal wool pressed with synthetic rubber. The determined by the experiment coefficient of friction between these materials is 0.56 . The rest of material data used in the study are summarized in Tab. 1. 
Selected properties of the brake disc material

Table 1

\begin{tabular}{|c|c|c|}
\hline \multirow{4}{*}{ Shaft material } & $\begin{array}{c}\text { Thermal } \\
\text { conductivity }\end{array}$ & $47 \mathrm{~W} \cdot(\mathrm{m} \cdot \mathrm{K})^{-1}$ \\
\cline { 2 - 3 } & \begin{tabular}{c} 
Density \\
\cline { 2 - 3 } Band material
\end{tabular} & $\begin{array}{c}\text { Thermal capacity at } \\
\text { constant pressure }\end{array}$ \\
\hline & $\begin{array}{c}\text { Thermal } \\
\text { conductivity }\end{array}$ & $4870 \mathrm{~kg} \cdot \mathrm{m}^{-3}$ \\
\cline { 2 - 3 } & $\begin{array}{c}\text { Density } \\
\text { Thermal capacity at } \\
\text { constant pressure }\end{array}$ & $30 \mathrm{Wg} \cdot(\mathrm{m} \cdot \mathrm{K})^{-1}$ \\
\hline
\end{tabular}

Of the many available research methods (field tests, bench tests, complete component tests, parts tests and simulation tests based on model - the advantages and disadvantages of each method are described more specific in a separate paper [28]), it was decided to perform simulation tests because of numerous benefits, e.g. low cost of research and short time of obtaining results [29-32]. Unfortunately, this method also has its drawbacks. It is necessary to develop a mathematical model that accurately reflects the actual physical phenomenon, otherwise the results may be loaded with a large error [3335].

Simulation research was carried out using the finite element method. The COMSOL Multiphysics software was used for this purpose (geometry was imported from SolidWorks). The mesh imposed on the developed model consisted of about 3000 elements, mostly triangular shaped, which gave nearly 17000 degrees of freedom. It is commonly used software in the braking process phenomenon [36-40] and in many other features [41-43].

It has been assumed that in the research the initial speed of the shaft will be: 1800, 2000 and 2200rpm. This speed range is due to different versions of the rotary mower prototype design - the designers experimented with various gear ratios. The simulation will cover only the braking process, not including the brake system turning on time. It was also assumed that there will be no additional sources of forces and torques that would reduce the rotational speed (like contact with the ground). Braking will take place at an ambient temperature of $20^{\circ} \mathrm{C}$, and the stopping time in each case is $1 \mathrm{~s}$. The diameter of cooperation is $100 \mathrm{~mm}$, and the width of the band is $20 \mathrm{~mm}$. Moreover, the following assumptions were made: unchanging coefficients of friction, stable and homogeneous contact pressure, homogeneous material of the brake pair and full surface contact, constant braking deceleration.

The retardation power of the braking process can be described as a negative derivative of the shaft's kinetic energy [44]:

$$
P=-m R^{2} \omega(t) \alpha
$$

where $m$-shaft mass, $\mathrm{kg}$;

$R$ - radius of the brake disc, $\mathrm{m}$;

$\omega-$ angular velocity, RPM

$t$ - time, s;

$\alpha$ - angular deceleration, $\mathrm{rad} \cdot \mathrm{s}^{-2}$.

Assuming that the braking deceleration is constant, we may say that:

$$
\omega(t)=\omega_{o}+\alpha t
$$

The retardation power is also expressed as the relation [45]:

$$
P=f_{f}(t) \cdot \omega(t) \iint r_{m} \cdot d A
$$

where $r_{m}$-radius of friction force (in this case $R=r_{m}$ ), $\mathrm{m}$.

$f_{f}$ - frictional force per surface unit;

$A-$ disc and pad contact surface area, $\mathrm{m}^{2}$.

Comparison of the two equations makes it possible to determine the $f_{f}$ coefficient: 


$$
f_{f}=-\frac{m R \alpha}{A}
$$

Assuming that the shaft deceleration occurs only through the action of the brake, the heat flux can be expressed using the equation [46]:

$$
q(r, t)=-f_{f} \cdot v_{d}(t)
$$

where $v_{d}=\omega(t) \cdot r_{m}-$ brake disc linear speed at radius $r_{m}, \mathrm{~m} \cdot \mathrm{s}^{-1}$;

or

$$
q(r, t)=-\frac{m R \alpha}{A} r_{m}\left(\omega_{o}+\alpha t\right)
$$

Amonton-Coulomb friction law $[47,48]$ makes it possible to determine the contact pressure, which in the analysed case is as follows:

$$
p=\frac{P}{\mu \cdot v}
$$

where $\mu$-coefficient of friction between the friction pair;

$P$ - total braking force, $\mathrm{N}$.

Also, the study takes into account the heat exchange occurring between the disc and pad, expressed as the following relation [49]:

$$
\rho \cdot C_{p} \frac{\partial T}{\partial t}+\nabla \cdot(-k \cdot \nabla T)=Q-\rho \cdot C_{p} \cdot u \cdot \nabla T
$$

where $\quad k$-thermal conductivity, $\mathrm{W} \cdot(\mathrm{m} \cdot \mathrm{K})^{-1}$;

$C_{p}$ - thermal capacity, $\mathrm{J} \cdot(\mathrm{kg} \cdot \mathrm{K})^{-1}$;

$u$ - heat flux rate, $\mathrm{W} \cdot \mathrm{m}^{-2}$;

$Q$ - heating power per density unit;

$\rho$ - density, $\mathrm{kg} \cdot \mathrm{m}^{-3}$;

$T$ - temperature, $\mathrm{K}$.

During the action of the brakes, the following amount of heat is released through convection and radiation:

$$
q_{d}=-h\left(T-T_{r}\right)-\varepsilon \sigma\left(T^{4}-T_{r}^{4}\right)
$$

where $\left(T-T_{r}\right)$ - temperature difference between the friction material and ambient temperature, $\mathrm{K}$;

$h$ - convection coefficient, $\mathrm{W} \cdot\left(\mathrm{m}^{2} \cdot \mathrm{K}\right)^{-1}$;

$\varepsilon$ - emissivity of material;

$\sigma-$ Stefan-Boltzman constant.

The relation between the convection coefficient and the linear speed of the brake disc at the radius $r$ is described as follows:

$$
h=\frac{0.037 k}{l}\left(\frac{\rho \cdot l \cdot v}{\mu_{v}}\right)^{0.8} \cdot\left(\frac{C_{p} \cdot \mu_{v}}{k}\right)^{0,33}
$$

where $\mu_{v}$ - viscosity, Pa.s;

$l$ - shaft diameter, $\mathrm{m}$.

\section{Results and discussion}

The direct result of simulation tests is temperature data of the tested elements. The measuring points were set $0.1 \mathrm{~mm}$ below the contact surface in the geometrical centre of the cooperation area. The temperature profiles of the brake disc and pad are shown in Fig. 3 and Fig. 4. Also, dissipated heat was calculated (Fig. 5). In addition, the amount of energy generated in the braking process was estimated for each case (Tab. 3). 
The obtained data were compared with the results of similar works by other researchers [50-52]. Although the results were presented in a slightly different form, the values are proportional. This allowed to assess the correctness of the research.

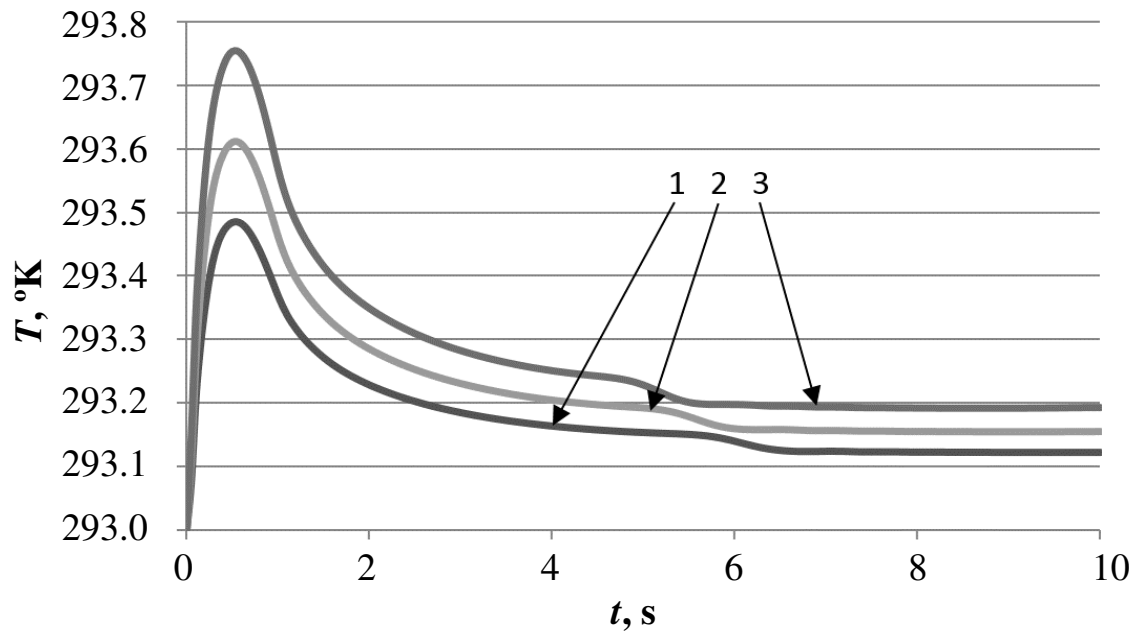

Fig. 3. Temperature profile of brake disc: 1 - initial speed $1800 \mathrm{rpm}$; 2 - initial speed 2000 rpm; 3 - initial speed 2200 rpm;

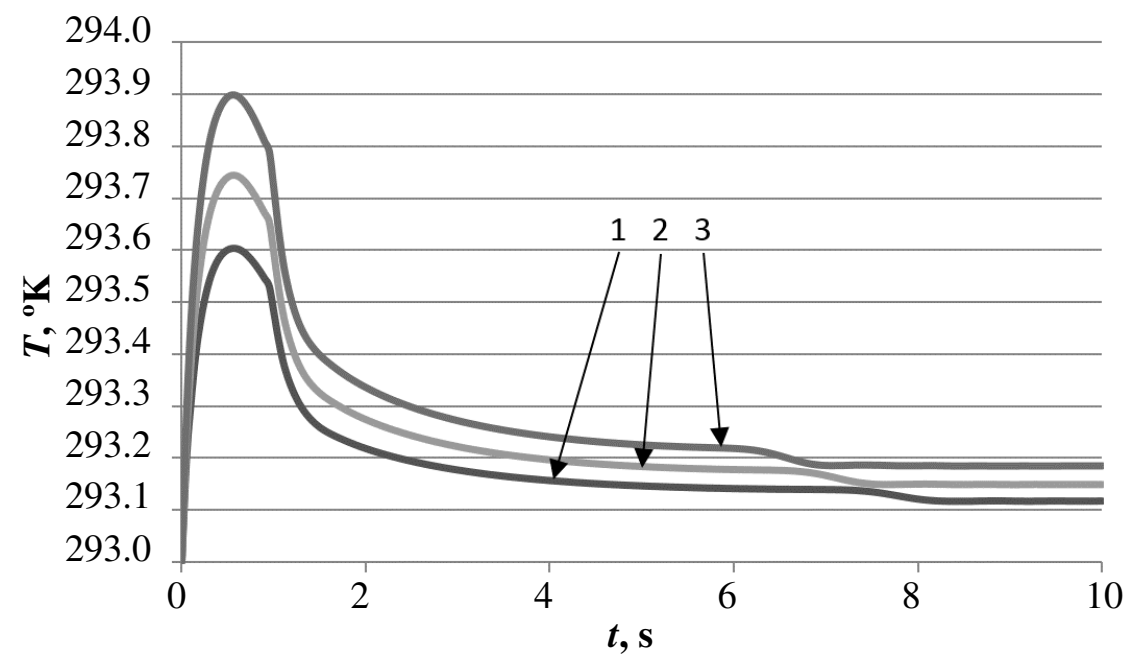

Fig. 4. Temperature profile of brake band: 1 - initial speed $1800 \mathrm{rpm}$; 2 - initial speed $2000 \mathrm{rpm} ; 3$ - initial speed $2200 \mathrm{rpm}$;

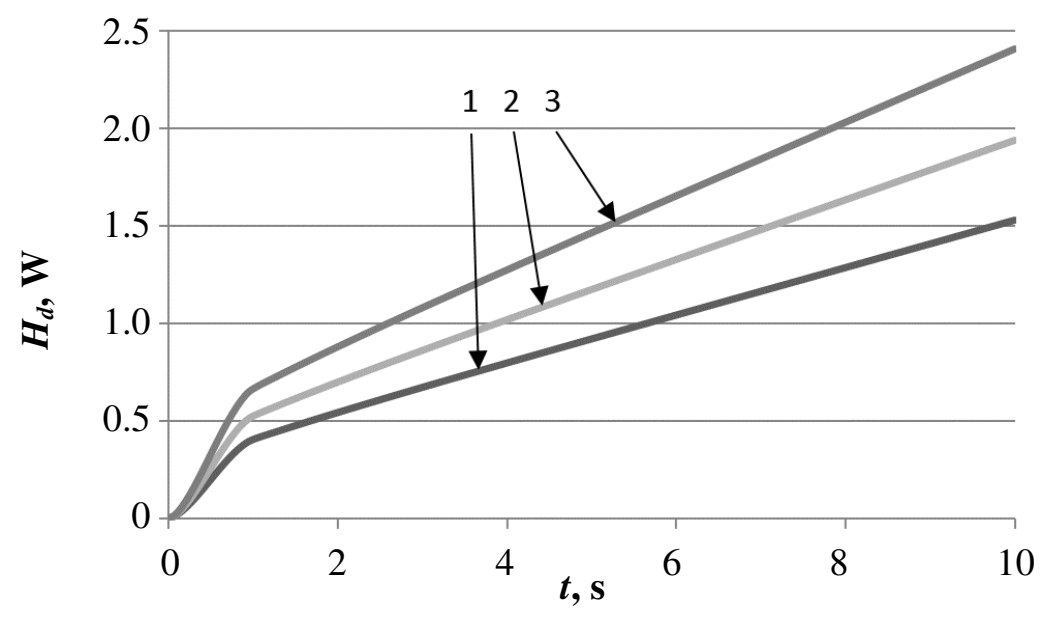

Fig. 5. Dissipated heat: 1 - initial speed $1800 \mathrm{rpm}$;

2 - initial speed 2000 rpm; 3 - initial speed 2200 rpm; 
Amount of energy generated in the braking process

Table 3

\begin{tabular}{|c|c|}
\hline Initial speed, rpm & Generated energy, W \\
\hline 1800 & 312.81 \\
\hline 2000 & 386.87 \\
\hline 2200 & 468.72 \\
\hline
\end{tabular}

Analyzing the obtained results, it can be seen how little energy is needed to stop the shaft in question, and how low temperature rise is generated on the friction elements of its brake. At measuring points, for all considered cases it increased by less than $1 \mathrm{~K}$. The initial speed difference did not significantly affect the results obtained. Between the lowest and highest initial speed, the difference in the brake temperature is only $\sim 0.3^{\circ} \mathrm{K}$. The charts also show characteristic "breaks". They are a result of different properties and volumes of interacting materials. The heat dissipated graph shows that heat is given off the fastest during the braking process. After its completion, it stabilizes in each case studied.

It should be remembered that in the most cases brake elements are made of a composite material, which resin is the matrix. It is a material that has limited resistance to heat load. Depending on the type of resin, damage to its structure may occur when heated to $400-500^{\circ} \mathrm{C}[53 ; 54]$. The weakest of them burn already at $260^{\circ} \mathrm{C}\left(533^{\circ} \mathrm{K}\right)$ [55]. In the studied cases, the temperature increase is so low that it will not cause a threat of material damage, and even less the phenomenon of fading. Mechanical stress may be more significant, however, it was not the subject of this study.

\section{Conclusions}

Braking systems of all kinds are extremely important for the safety of users. The health or even life of many people may depend on their correct functioning. It is also very important to correctly design the brakes, which should not overheat. Too high temperature can lead to the fading phenomenon, with can cause a COF value drop, even to zero. This study proposes a methodology for simulation research of the working elements of agricultural machinery braking systems heating up process. Based on this method several different cases with different initial shaft rotation speeds were analysed. A number of simplifying assumptions were made to avoid unnecessary mesh compaction and to reduce the time needed to perform a single test.

As the result of the tests it was found that:

1. Development of a mathematical model requires knowledge of a number of facts, both geometrical of the examined element, as well as related to the considered phenomenon.

2. The performed simulation tests based on the developed model allowed to measure the temperature of the braking system components at any time and at any point.

3. The highest temperatures were achieved when braking from $2200 \mathrm{rpm}$. Temperature rise is $0.76^{\circ} \mathrm{K}$ on the shaft brake disc surface, and $0.9^{\circ} \mathrm{K}$ in the band measuring point.

4. The degree of heating is low for all considered cases, so there is no risk of overheating and thermal damage to the material.

The obtained results show that the examined peripheral brake has been designed with a high safety margin. Therefore, it can be successfully used to brake much heavier shafts or rotating with higher speeds.

\section{Funding}

This publication was financed through the program of the Ministry of Science and Higher Education of Poland named "Regional Initiative of Excellence" in 2019-2022 project number 011/RID/2018/19.

\section{Acknowledgments}

This research was co-founded through the subsidy of the Ministry of Science and Higher Education for the discipline of Mechanical Engineering at the Faculty of Mechanical Engineering, Bialystok University of Technology. 


\section{References}

[1] Siddic S.A. Appropriate Technologies for Improving Yield and Income of Small Holders Growing Rice Paddy in Rainfed Low Lands of Agro-Biodiversity Hotspots in India. Agricultural Sciences, vol. 10(11), 2019, pp. 1497-1505.

[2] Dawe D., Pandey S., Nelson A. Emerging Trends and Spatial Patterns of Rice Production. Rice in the Global Economy: Strategic Research and Policy Issues for Food Security, Philippines, Los Baños: IRRI, 2010, pp. 15-35.

[3] Guth M., Smędzik-Ambroży K., Czyżewski B., Stępień S. The Economic Sustainability of Farms under Common Agricultural Policy in the European Union Countries. Agriculture, vol. 10(2), 2020, 20p.

[4] Bello R.S. Farm Tractor Systems: Maintenance \& Operation. California, US: Createspace Independent Pub, 2012, 386 p.

[5] Aikins K. A., Afriyie J. K., Amanor I. N., Ackah S. M., Bobobee E. Y. H. Assessment of Tractor Maintenance Practices of Tractor Operators at Ejura, Ghana. International Journal of Science and Engineering Applications, vol. 5(5), 2016, pp. 257-267.

[6] Kamandar M.R. The Selection, Designing and Analysis of Heavy Duty Tractor Gearbox (ITM8200). Applied Mechanics and Materials, vol. 110-116, 2012, pp. 2948-2957.

[7] Gouvea da Silva C.A., Rodrigues de Sá J.L., Menegatti R. Diagnostic of Failure in Transmission System of Agriculture Tractors Using Predictive Maintenance Based Software. AgriEngineering, vol. 1, 2019, pp. 132-144.

[8] Smil V. Still the Iron Age: Iron and Steel in the Modern World. England: Elsevier, 2016, 280 p.

[9] Nemeck T., Kagi T. Life Cycle Inventories of Agricultural Production Systems. Switzerland: Art, 2007, 360p.

[10] Jacobs C. William R.H. Agricultural power and machinery. NYC: Mc-Garw Hill Book Company, 1983, 101p.

[11] Streppel A.H., Klingenberg W., Singh U.P. Advances in Sheet Metal Forming Applications. International Journal of Machine Tools and Manufacture, vol. 48(5), pp. 483-608.

[12] Mieczkowski G. Description of stress fields and displacements at the tip of a rigid, flat inclusion located at interface using modified stress intensity factors. Mechanika, vol. 21(2), 2015, pp.91-98.

[13] Szpica D. New Leiderman-Khlystov Coefcients for Estimating Engine Full Load Characteristics and Performance. Chinese Journal of Mechanical Engineering, vol. 32, 2019, 14p.

[14]Borawski A. Simulation Study of the Process of Friction in the Working Elements of a Car Braking System at Different Degrees of Wear. Acta Mechanica et Automatica, vol. 12(3), 2018, pp. 221-226.

[15] Czaban J., Szpica D. Drive test system to be used on roller dynamometer. Mechanika, vol. 19(5), 2013, pp. 600-605.

[16] Jewtuszenko O., Kuciej M., Topczewska K. Some theoretical model for determining the temperature field of a multi-disk brake. Advances in Mechanical Engineering, vol. 12(1), 2020, pp. 1-15.

[17] Kuciej M., Topczewska K. Determination of the Maximum Temperature of the Friction Pad in a One-Disk Clutch. Materials Science, vol. 54(6), 2019, pp. 819-826.

[18] Yan M., Xu J. Prediction Model for Brake-Drum Temperature of Large Trucks on Consecutive Mountain Downgrade Routes Based on Energy Conservation Law. Mathematical Problems in Engineering, vol. 11, 2018, pp. 1-10.

[19] Adamowicz A. Thermal stress state of the pad-disc tribosystem ad single braking. Journal of Friction and Wear, vol. 38(2), 2017, pp. 24-30.

[20] Jamrozik A., Tutak, W. A Study of Performance and Emissions of Si Engine with a Two-Stage Combustion System. Chemical and Process Engineering, vol. 32(4), 2011, pp. 453-471.

[21] Cupiał K., Jamrozik A. SI engine with the sectional combustion chamber. Journal of KONES, vol. 9(3-4), 2002, pp. 62-66.

[22] Szpica D. Coefficient of Engine Flexibility as a Basis for the Assessment of Vehicle Tractive Performance. Chinese Journal of Mechanical Engineering, vol. 32, 2019, 9p.

[23] Kamiński T.M., Wendeker M., Urbanowicz K., Litak G. Combustion Process in a Spark Ignition Engine: Dynamics and Noise Level Estimation. Chaos, vol. 14(2), 2004, pp. 461-6. 
[24]Bos J., Moes H. Frictional Heating of Tribological Contacts. Journal of Tribology, vol. 117(1), 1995, pp. 171-177.

[25] Mieczkowski G. Static electromechanical characteristics of piezoelectric converters with various thickness and length of piezoelectric layers. ActaMechanica et Automatica, vol. 13(1), 2019, pp30-36.

[26] Mieczkowski G., Borawski A., Szpica D. Static electromechanical characteristic of a three-layer circular piezoelectric transducer. Sensors, vol. 20, 2020, 222, pp. 1-14.

[27] Borawski A. Suggested Research Method for Testing Selected Tribological Properties of Friction Components in Vehicle Braking Systems. Acta Mechanica et Automatica, vol. 10(3), 2016, pp. 223-226.

[28] Borawski A. Common methods in analysing the tribological properties of brake pads and discs - a review. Acta Mechanica et Automatica, vol. 13(3), 2019, pp. 189-199.

[29] Mieczkowski G. Electromechanical characteristics of piezoelectric converters with freely defined boundary conditions and geometry. Mechanika, vol. 22(4), 2016, pp. 265-272.

[30] Towoju O.A. Braking Pattern Impact on Brake Fade in an Automobile Brake System. Journal of engineering sciences, vol. 6(2), 2019, pp. 11-16.

[31] Jewtuszenko O., Kuciej M., Och E. Influence of thermal sensitivity of the pad and disk materials on the temperature during braking. International Communications in Heat and Mass Transfer, vol. 55, 2014, pp. 84-92.

[32] Yevtushenko O., Grzes P. 3D FE model of frictional heating and wear with a mutual influence of the sliding velocity and temperature in a disc brake. International Communications in Heat and Mass Transfer, vol. 62, 2015, pp.37-44.

[33] White P., Ingalls R.G. Introduction to Simulation. Proceedings of "2009 Winter Simulation Conference, WSC 2009”, December 13-16, 2009, Hilton Austin Hotel, Austin, TX, USA, pp. $12-$ 16.

[34] Moffat J., Passman M. Metamodels and emergent behaviour in models of conflict. Simulation Modelling Practice and Theory, vol. 12(7-8), 2004, pp. 579-590.

[35] Franklin A.F., Leighton K., Cantrell M.A. Rutherford-Hemming T. Simulation Research for Academics: Novice Level. Clinical Simulation in Nursing, vol. 11(4), 2015, pp. 214-221.

[36] Kalikatea S.M.,.Patila R.S., Sawantbham S.M. Simulation-based estimation of an automotive magnetorheological brake system performance. Journal of Advanced Research, vol. 14, 2018, pp. 43-51.

[37] Day A.J, Ho H.P., Hussain K., Johnstone A. Brake system simulation to predict brake pedal feel in a passenger car. Warrendale, PA: SAE International. Report No. 09BC-0077.

[38] Yang C., Dang J. Simulation Research on Braking Test Model of Speed Signal. Proceedings of "2016 International Conference on Control and Automation (ICCA 2016)", June 1-3, 2016, Kathmandu, Nepal, pp. 20-27.

[39] Day T.D., Roberts S.G. A Simulation Model for Vehicle Braking Systems Fitted with ABS. Journal of Passenger Car: Mechanical Systems Journal, vol. 111(6), 2002, pp. 821-839.

[40] Kozłowski M., Choromański W. Simulation research of driveability of the ECO electric car. The Archives of Transport, vol. 17-18(3-4), 2013, pp. 103-110.

[41] Pal A., Pal M. IoT for Vehicle Simulation System. vol. 7(2), 2017, pp. 4393-4402.

[42] Sahla A., Hajrizi E., Likaj R. Modelling and Simulation of road Vehicle. IFAC Proceedings Volumes, vol. 43(25), 2010, pp. 65-68.

[43] Ilke I.Y., Cömert S., Gül E,, Tuna B. Modelling and simulation of power steering system for agricultural tractors. International Journal of Advances on Automotive and Technology, vol. 1(3), 2017, pp. 109-113

[44] Richardson J.M., Coulson J.F. Chemical Engineering Vol. 1: Fluid Flow, Heat Transfer and Mass Transfer, Bath: The Bath Press, 1999, 908p.

[45]Peng H., Hu J.S. Traction/Braking Force Distribution for Optimal Longitudinal Motion During Curve Following. Vehicle System Dynamics, vol. 26(4), 1996, pp.301-320.

[46] Talati, F., Jalalifar, S. Analysis of heat conduction in a disk brake system. Heat Mass Transfer, vol. 45, 2009, pp. 1047-1059.

[47] Popova E., Popov V.L. The research works of Coulomb and Amontons and generalized laws of friction. Friction. vol. 3(2), 2015, pp. 183-190. 
[48] Barber J.R. Multiscale Surfaces and Amontons' Law of Friction. Tribology Letters, vol. 49, 2013, pp. 539-543.

[49] Carey V.P., Chen G., Grigoropoulos C. A Review of Heat Transfer Physics. Nanoscale and Microscale Thermophysical Engineering, vol. 12(1), 2008, pp 1-60.

[50]Eriksson M., Lord J., Jacobson S. Wear and contact conditions of brake pads: dynamical in situ studies of pad on glass. Wear, 249, 2001, pp. 272-278.

[51] Incropera F.P., DeWitt D.P. Fundamental of heat and mass transfer. New York: John \&Wiley Sons. Inc, 2007, 1070.

[52] Wolff A. A method to achieve comparable thermal states of car brakes during braking on the road and on a high-speed roll-stand. The Archives of Transport, vol. 22(2), 2010, pp. 259-273.

[53]Zeng S., Zhang H., Meng Y. Research on Heat Conduction Inverse Problem of Continuous Long Downhill Truck Brake, Proceedings of "International Conference on Civil, Transportation and Environment (ICCTE 2016)", January 30-31, 2016, Guangzhou, China, pp. 407-416.

[54] Komori T., Miyake S., Senoo Y. Brake friction material (US Pat. 4954536). USA: United States Patent and Trademark Office, 1990, 5p.

[55] Kakegawa H., Yasuda T., Wang X. Binder Composition for Friction Materials, and Friction Materials (US Pat. 5889081). USA: United States Patent and Trademark Office, 1999, 10 p. 